Führungsseminar 2013-2014 für Oberärztinnen und Oberärzte Leitende Ärztinnen und Leitende Ärzte aller Fachgebiete

\title{
Sicherheit gewinnen in häufigen Führungssituationen
}

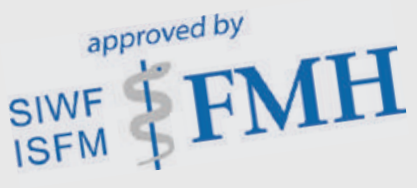

\begin{abstract}
Um als Kaderarzt die täglichen Führungsaufgaben erfolgreich meistern zu können, genügt Fachkompetenz alleine nicht. Dazu braucht es solide Kenntnisse der Führungsgrundlagen und praxisbewährte Tools.
\end{abstract}

Im praxisbezogenen Führungsseminar setzen sich die Oberärztinnen und Oberärzte sowie Leitende Ärztinnen und Leitende Ärzte mit den häufigsten Führungssituationen des Spitalalltags auseinander und lernen dabei die wichtigsten Führungsprinzipien und Führungstools kennen, um sie in der Praxis richtig einzusetzen. Es wird explizit auf die Fragestellungen der Teilnehmenden eingegangen. Gleichzeitig bietet der Kurs die einmalige Möglichkeit, von den persönlichen Erfahrungen gleichgestellter Kolleginnen und Kollegen zu profitieren. Die vier Module ( $4 \times 2$ Tage) werden von qualifizierten und erfahrenen Experten begleitet und beinhalten die wichtigsten führungsrelevanten Themen.

\section{Inhalte (Auszug)}

- Effiziente Gesprächsführung, das schwierige Gespräch, Kritik erteilen, Anstellung, Qualifikation, Zielvereinbarung, Sitzungsleitung.

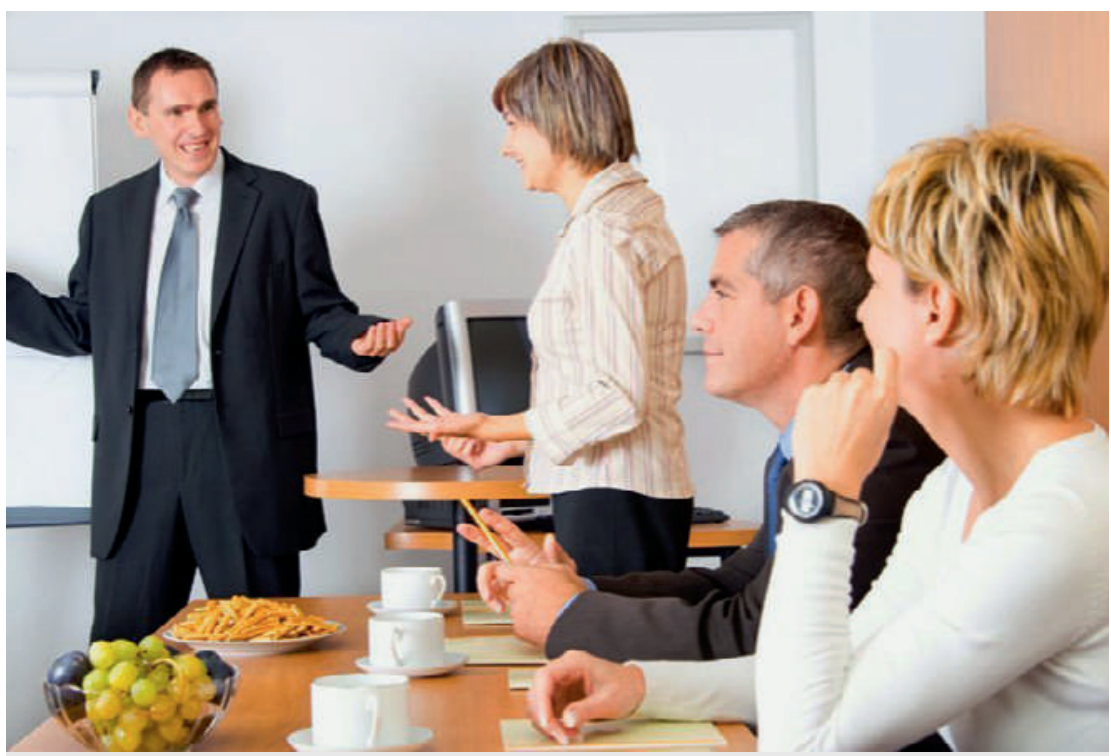

Das Führungsseminar richtet sich an Oberärztinnen und Oberärzte und Leitende Ärztinnen und Leitende Ärzte aller Fachbereiche.
- Ärzte als Führungspersonen, Führungsprinzipien und Führungsmethoden, Reflexion der eigenen Führungskompetenz, wirkungsvolles Führen in komplexen Organisationen.

- Team und Teamentwicklung, Konfliktmanagement, eigenes Verhalten in Konfliktsituationen, Harvard Modell, Interventionsmöglichkeiten.

- Prioritätensetzung und Zeitmanagement als Kaderärzte, Assessment-Methoden, eigene Erfolgspotentiale, Bewerbung und Vorstellung für Kaderstellen.

Das Seminar wird vom Schweizerischen Institut für Weiter- und Fortbildung (SIWF) der FMH für die Fortbildung akkreditiert und mit 32 Credits anerkannt.

\section{Daten}

4. und 5. November 2013

2. und 3. Dezember 2013

30. und 31. Januar 2014

13. und 14. März 2014

\section{Seminarort}

Kongress und Kursaal AG Bern

\section{Kurskosten}

5300 Franken für 8 Seminartage inkl. Mittagessen, Pausenverpflegungen, Infrastruktur und ausgiebige Kursunterlagen.

\section{Anmeldeschluss 15. August 2013}

\author{
Informationen und Anmeldungen \\ biaggi-partner, führungsseminare \\ Kurssekretariat \\ Postfach 15 \\ CH-3074 Muri \\ Tel. 0319517234 \\ jean.biaggi[at]bluewin.ch \\ www.biaggi-partner.ch
}

